\title{
Biomodels for the medicine teaching
}

\begin{abstract}
At present, technology has made great progress, allowing tools that in the past were only used for a specific task and be applied to solve different purposes. This is the case computed tomography that was only used for medical diagnoses by means of two-dimensional visualization (sagittal, coronal and transverse cuts) or three-dimensional representations, when placing one cut over another. However, this visualization can have a better use, since it is possible that, through specialized tools such as three-dimensional reconstruction, a biomodel whith a great biofidelity is a achieved allowing a better an understanding of a human body's zone. In addition, Biomodels can be used for teaching, training and planning in both medical areas and Biomechanics.
\end{abstract}

Keywords: biomodel, biofidelity, medical
Volume 3 Issue 5 - 2019

\author{
Mastache Miranda OA, Urriolagoitia Sosa \\ G, Hernández Vázquez RA, Marquet Rivera \\ RA, Torres Yáñez A, Romero Ángeles B, \\ Urriolagoitia Calderón G \\ Instituto Politécnico Nacional, México
}

Correspondence: Octavio Alejandro Mastache Miranda, Instituto Politécnico Nacional, Higher School of Mechanical and Electrical Engineering, Gustavo A Madero Delegation, C.P. 07320, Mexico,Email amastache@esimez.mx

Received: October 15, 2019 | Published: October 31, 2019

\section{Introduction}

Traces have been found that the human being, since prehistory, has been attracted to observe the functioning of his body. All this has been verified through paintings and images in the caverns, papyri and records that have been found throughout history, where foundations of the observation of the body and its operation are found. In the medical areas it has become important to simulate biological tissues, since this allows experimentation or testing without the need to affect patients. These simulations are carried out by means of computational tools, which allow emulating the human body. This is why, in this work, the proposal of the concept of medical education, based on numerical simulations, is made as this facilitates the acquisition of learning, skills and experiences necessary for patient care. ${ }^{1,2}$ To achieve this goal, Medicine, among other tools, is helped by imaging, which is responsible for obtaining Biological images through various imaging studies (radiographs, tomographs or resonances, etc.), which allow two-dimensional and even three-dimensional visualization of the human body, making it possible to differentiation hard (bone) and soft tissues (muscles, tendons, cartilage, etc.) (Figure 1).

However, visualization is not enough. It is also required the use of specified teaching tools to allow of manipulation of imagen that could lead to understanding and a good practice. For this reason the use of Biomodels is required to fulfill this function of being manipulative teaching tools, unlike radiographs, tomographs or resonances, with which only visualization is possible. Biomodels are threedimensional entities with which the medical student or advanced researching interacts according to their needs. These can be from the teaching-learning process, diagnosis, presurgical evaluation to make impressions in rapid prototyping, allowing practice advance leading even make custom prostheses.

Biomodels are commonly used in computational biomechanics, since, thanks to their biofidelity, they allow, through numerical analysis, the study the mechanical behavior of external or internal factors that act on the various anatomical structures. ${ }^{3}$ These analyzes are generally carried out, using the finite element method (Figure 2). The realization of the Biomodels is possible thanks to the use of DICOM files generated by tomographs and the magnetic resonance, since these present a series of cuts of the tissues with quality that allows the reconstruction of the Biomodels and their differentiation between the hard and soft tissues that conform certain anatomical structures (Figure 3). ${ }^{4}$

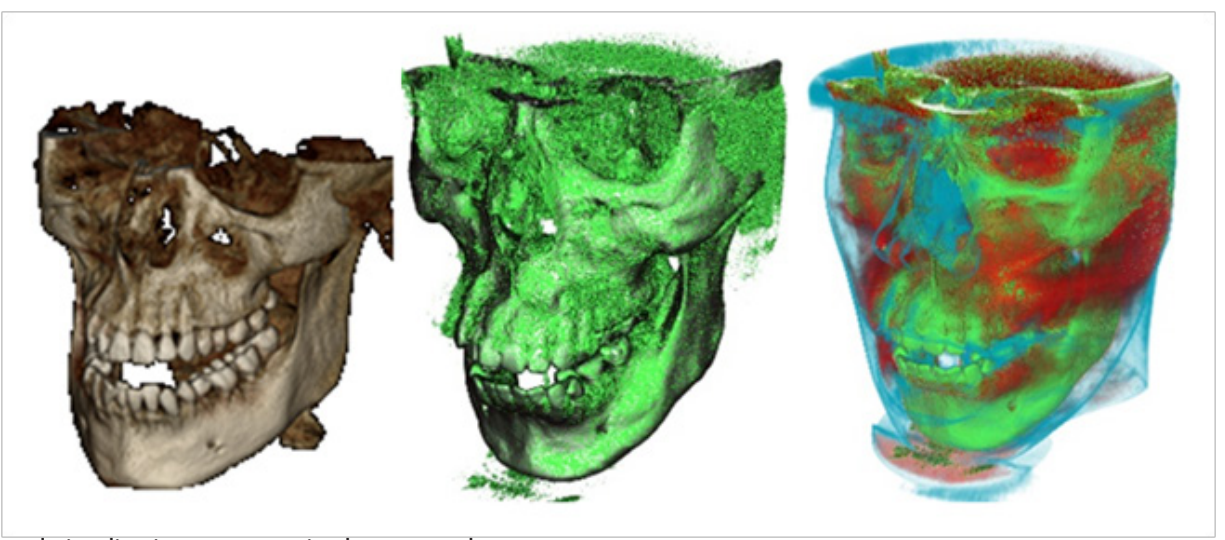

Figure I Three-Dimensional visualization computerised tomography. 

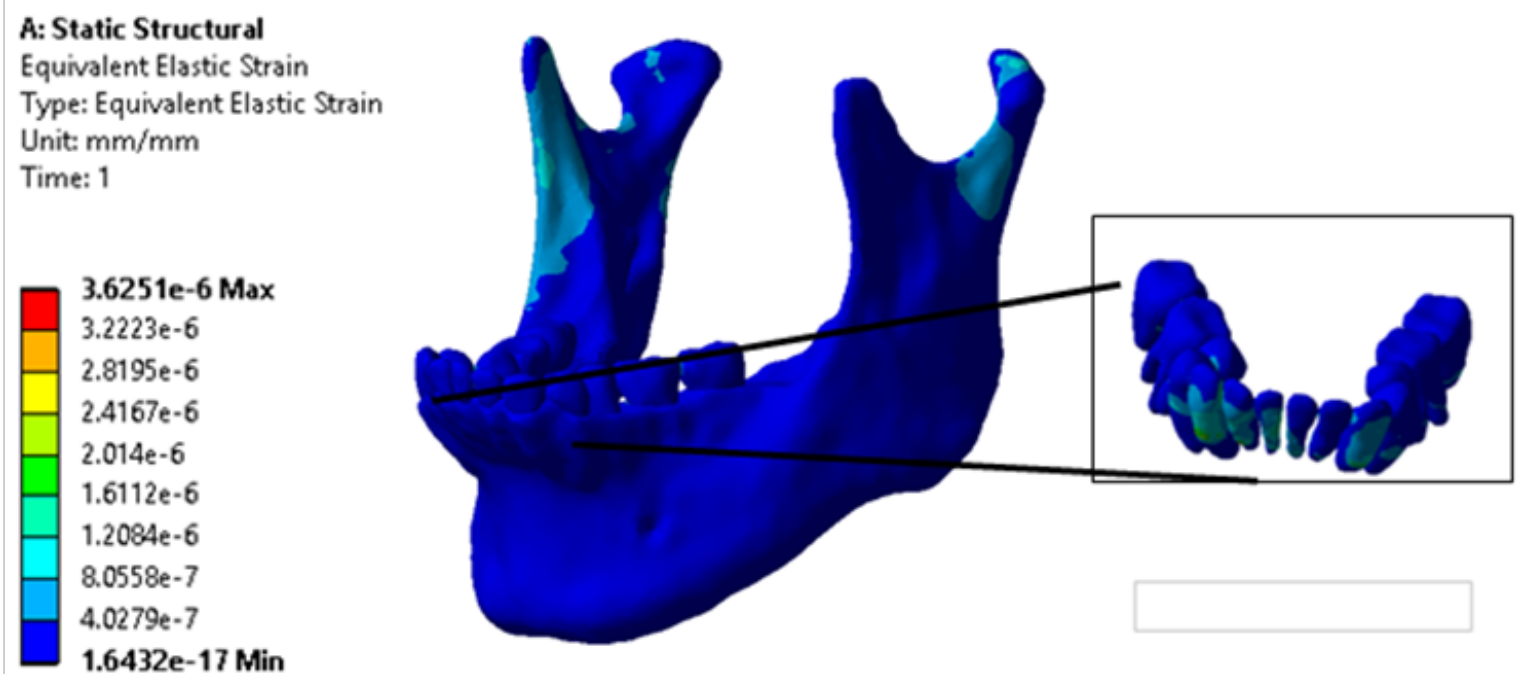

Figure 2 Numerical analysis exemplification of jaw.
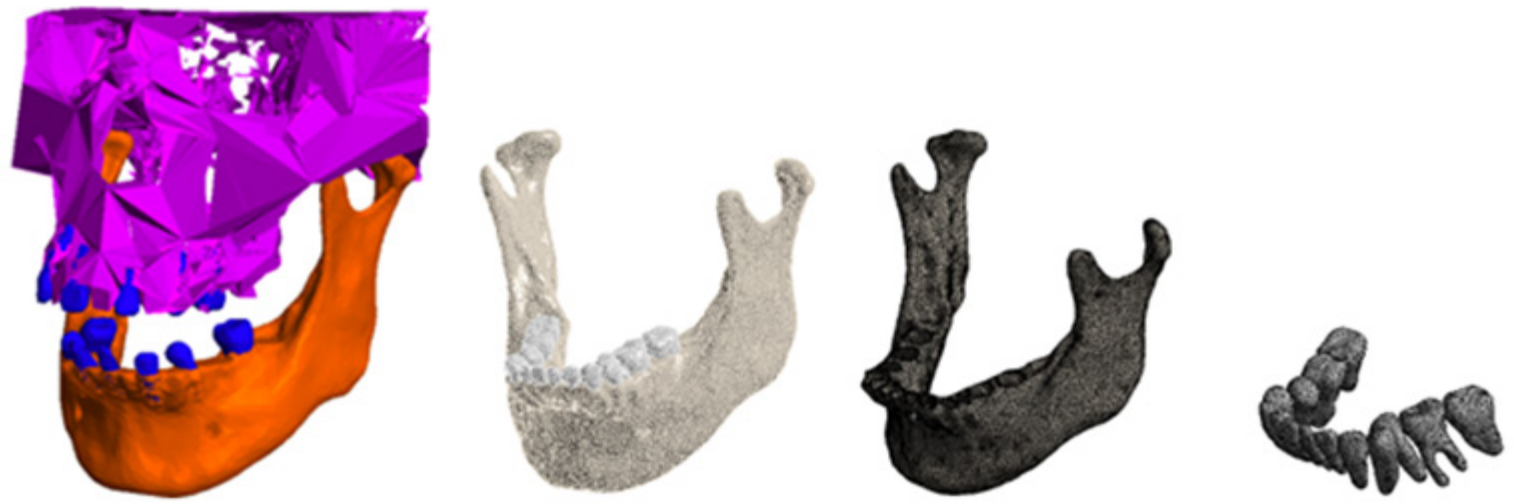

Figure 3 Three dimensional reconstruction (Biomodel) of the jaw.

\section{Conclusion}

Nowadays thanks to the cooperation of the various areas (medicine, mechanics, biomechanics, etc.) it is possible to improve the understanding and compression of the human body, helping to create tools that contribute to form and training human resources biomaterial production, prosthesis development and everything in a personalized way, maximizing response times for diagnosis and treatment, as well as to provide aesthetic options. So the use of these new non-invasive techniques, based on simulation facilitates the propose and creating of innovative treatments and facilitate the compression of the human body, thus improving work being carried out between different areas.

\section{Acknowledgements}

The authors gratefully acknowledge the financial support from the Mexican government by de Consejo Nacional de Ciencia y Tecnología and the Instituto Politécnico Nacional.

\section{Funding details}

None.

\section{References}

1. Dávila Cervantes A. Simulation in Medical Education. Investigación en educación médica. 2014;3(10):100-105.

2. Argullós JLP, Sancho CG. The use of simulations in medical education. Teoría de la Educación. Educación y Cultura en la Sociedad de la Información. 2010;11(2):147-169.

3. Marquet Rivera RA. Numerical analysis of anterior cruciate ligament injury in three different degrees of damage. Master Thesis. Instituto Politécnico Nacional. 2018. p. 68-96.

4. Mastache Miranda OA. Modeling by tomography of volumes of bone structures for numerical simulation under the action of external loads and/ or agents. Master Thesis, Instituto Politécnico Nacional. 2016. p. 24-27.

\section{Conflict of interest}

The authors declare there is no conflict of interests. 